\title{
Genetically modified rabbits as bio-producers and biomodels
}

\author{
E $M$ Koloskova $^{1, *}, V A$ Ezerskiy $^{1}, T P$ Trubitsyna $^{1}$, and $N V$ Belova $^{1}$ \\ ${ }^{1}$ All-Russian Research Institute of Physiology, Biochemistry and Animal Nutrition - Branch of the \\ Federal Science Center for Animal Husbandry named after Academy Member L. K. Ernst, Borovsk, \\ Kaluga Region, 249013, Russia
}

\begin{abstract}
Genetically modified (GM) animals are necessary to solve the global problems of humanity related to nutrition and health. Rabbits, as laboratory, domestic and farm animals, occupy a special niche in research. GM rabbits are promising as bioreactors for producing biologically active (BA) proteins with milk or blood, and are in demand in Biomedicine as biomodels of diseases. To date, many GM rabbits-biomodels, producers of recombinant proteins have been created in the world using CRISPR/Cas9 technology. All-Russian Research Institute of Animal Physiology, Biochemistry and Nutrition has experience in obtaining transgenic rabbitsproducers of human BA proteins with milk by microinjecting recombinant DNA into zygote pronuclei. The possibility of site-specific modification of the rabbit whey acidic protein (WAP) gene using CRISPR/Cas9 technology is discussed. A DNA matrix containing homology arms to the WAP rabbit gene and site-specific CRISPR/Cas9 components in plasmid form were obtained. Microinjections of rabbit zygotes were performed and embryo survival was evaluated in vitro. The efficiency of using the green fluorescent protein gene under the cytomegalovirus promoter in the DNA matrix as an indicator of homologically directed repair was evaluated. This work can be useful for obtaining rabbits that produce with milk BA protein instead of WAP.
\end{abstract}

\section{Introduction}

The main goals of obtaining genetically modified animals are to change the characteristics of animals, to acquire new opportunities for them, to eliminate some negative qualities in the desired direction for humans. Using genetic engineering methods, it's possible to obtain animals with new qualities like resistance to various diseases, increased productivity, changed characteristics of milk, meat, blood, etc. More than a dozen biologically active proteins have already been obtained from GM animals (cows, pigs, goats, rabbits, and sheep). As living self-replicating bioreactors, they are much more cost-effective than biotechnological or chemical production of similar substances. Transgenic animals that secrete with milk valuable proteins, such as antibodies, enzymes, blood clotting factors, and others, are increasingly used as bioreactors-producers of biologically active human

\footnotetext{
* Corresponding author: heleko3@yandex.ru
} 
proteins. Genetically modified animals are also used in biomedicine for studying the molecular basics of human diseases and for modeling diseases [1]. The rabbit is the smallest animal used both in laboratory practice and in animal husbandry, from which recombinant pharmaceutical proteins can be obtained on an experimental and industrial scale. In contrast to the mouse model, the rabbit has a number of advantages. It has been used for studying human diseases for a long time, and it is used as a biomodel for evaluating the general toxic effect of biologically active agents and pharmaceuticals. During the last two decades, rabbits, especially GM ones, are becoming increasingly popular in the field of biomedicine [2-4]. Rabbits quickly reach sexual maturity, have a short gestation period, and produce large offspring with relatively simple maintenance.

From different ways to create gene modifications in animals, such as pronuclear microinjection (MI), the using of viral constructions, the using of embryonic stem cells (ESC), the method of somatic cell nuclear transfer (SCNT), MI is the most convenient and often used. The first transgenic rabbit was obtained by the classic method of microinjection of the DNA structure in the zygote pronucleus as far back as 1985, but the efficiency of creating transgenic large low-yielding animals in this way remained extremely low for a long time. In contrast to mice, the technology of using ESC practically did not work on rabbits and the SCNT method had very low efficiency [5]. The first rabbit with a knockedout gene (KO) was obtained by SCNT method just in 2015 [6]. Meanwhile, rapidly developing new endonuclease methods of genome editing made it possible to obtain animals of different species, including rabbits, with KO-genes [7].

With the advent of genomic editing methods based on new endonuclease technologies (ZFN, TALEN, and CRISPR/Cas9), the efficiency of obtaining GM animals by microinjection increased several times, this made a relatively simple method of zygotes microinjecting quite acceptable for low-yielding animals. In 2011, using ZFN (zinc-finger nucleases), there was obtained the first GM rabbit with site-specific modificationdestruction of the locus of the immunoglobulin $M$ gene [8]. This technology has been applied to create rabbits with knockout of Apolipoprotein C-III and Apolipoprotein E genes [9; 10], cholesterol ester transfer protein (CETP) [11] in 2017. At about the same time, using TALEN (transcription activator-like effector nucleases) technology, there were created rabbits with the knockout of protein-recombinase Rag1, Rag2 (Recombination activating gene) [12] and fumarylacetoacetate hydrolase genes [13].

From a superovulating rabbit, 30-50 oocytes/embryos can be extracted, and up to $50 \%$ of the embryos develop after their microinjection by components of one endonuclease system or another. After their transplantation to the fallopian tubes, the recipient rabbits produce $30-50 \%$ offspring, whose GM efficiency can reach $100 \%$.

In comparison with classical transgenesis, modern technologies make it possible to obtain animals with an extended range of modifications (knockout of one or more target genes at the same time, site-specific insertion (knock-in, KI) of a specific genomic sequence) in application to fertilized eggs using the MI method with very high efficiency.

The production of biologically active proteins is an important field of rabbit application, including transgenic ones: rabbit monoclonal antibodies (mAbs) from using for just scientific purposes get an increasing therapeutic and diagnostic application. Nivolumab and atezolizum (mAbs to the PD-1: programmed cell death receptor) are demanded in targeted cancer immunotherapy.

Rabbit gene sequences have more homology with human genes than rodent genes. Early embryogenesis and gastrulation (the process of germ layers formation) of rabbits are closer to humans, what allows using them as a reproductive model: the teratogenic effect of thalidomide, which was not shown in mice, was confirmed in rabbits. Lung diseases, its pathophysiology, and inflammatory reactions of the rabbit model are comparable to those found in humans: they are used in medical tests for allergic reactions, as a model for 
studying stem cell therapy, and eye diseases. Modeling of tumors in rabbits has been used for a long time: VX2 tumor transplantation (squamous cell carcinoma) is carried out in experimental oncology to model malignant neoplasms of the head and neck, kidney, brain, liver, in the study of colorectal cancer with liver metastases.

Since 2013 using CRISPR/Cas9 (clustered regularly interspaced short palindromic repeats) technology there were produced GM rabbits:

1) with knockout of one or simultaneously several genes encoding more than 30 proteins, for example, apolipoproteins, myostatin, tyrosinase, etc.;

2) with integrated, knock-in (KI), gene modifications;

3) with point modifications of the gene in order to knock out or change the properties of the protein encoded by it.

The ROSA26 locus is often used to create GM animals with a predictable transgene expression profile. Transcripts of this locus that do not encode RNA are expressed in all tissues. Integration of the transgene in this locus by homologous recombination in particular, does not cause adverse effects on viability and allows obtaining stable expression of the transgene throughout the body. In this way, hundreds of TG animals were created, primarily mice, and cell lines expressing various transgenes. For example, the expression of the green protein was carried out in all tissues of transgenic rabbits obtained as a result of site-specific integration of the enhanced green fluorescent protein (EGFP) gene into the Rosa26 locus by homologous recombination repair mechanism.

In recent years, using CRISPR/Cas9 technology there were produced GM rabbitsmodels of such human diseases as: cardiovascular (hypertrophic cardiomyopathy, atherosclerosis, arterial thrombosis); immune diseases, including immunodeficiency; infectious diseases; metabolic syndromes due to both nutrition and heredity; Xchromosome-related diseases - hypophosphatemia (a common cause of inherited rickets) and Duchenne Muscular Dystrophy; progeria syndrome; hermaphroditism; ectodermal dysplasia; cleft palate; Wilson's disease (copper metabolism disorder, leading to severe hereditary diseases of the Central nervous system and internal organs); models were created to study the metabolism of lipids and lipoproteins [14].

The promoter regions of genes of tissue-specific proteins of cow, goat or sheep milk (casein, whey proteins) are used for producing transgenic animals-producers of BA proteins with milk as part of genetic constructs. Those transgenic animals are able to synthesize human protein exclusively in the mammary gland and secrete it into milk from which it can be extracted. Promotional sequences of the whey acidic protein (WAP) gene in mouse and rabbit milk were used as part of recombinant DNA in the production of the first transgenic animals. The protein content in rabbit milk is significantly higher than in cow's milk (14\% vs. $5 \%$ ), and up to $160 \mathrm{~g}$ of milk can be obtained from lactating rabbit per day [15]. GM rabbits are used for the production of pharmacological proteins with milk, which are not required in large quantities. In 2014, the US food and drug administration (FDA) approved Ruconest (manufactured by the Dutch pharmaceutical company Pharming Group $\mathrm{NV}$ ), the first drug to be a recombinant human $\mathrm{C} 1$ esterase inhibitor designed to treat acute angioedema in patients with a hereditary disease. Recombinant human C1 esterase inhibitor, which is part of the drug, is extracted from the milk of transgenic rabbits obtained by classical transgenesis using the bovine casein alpha-S1 gene promoter in the gene design. The target protein content in rabbit milk reached $12 \mathrm{~g} / 1$ [16].

Rotavirus (RV) is the leading cause of viral gastroenteritis in newborns, so the component proteins (VP2 and VP6) of virion can be considered as potential candidates for vaccine creation. TG rabbits were obtained, whose milk could be used as a source of rotavirus antigens, but the content of simultaneously secreted recombinant proteins VP2 and VP6 in milk was less than $1 \mathrm{mg} / \mathrm{ml}$. The viral proteins expressed were immunogenic. Rectal introduction of partially purified milk proteins VP2 and VP6NG (non-glycosylated 
form) with an adjuvant almost completely prevented diarrhea in mice infected with a mouse strain of the virus $[17,18]$. In 2019, GM rabbits with the VP6 gene integrated into the $\beta$ casein locus (CSN2) were obtained using the CRISPR / Cas9 technology to create a rotavirus vaccine suitable for both mammary-gland-based production and milk-based introduction [19]. For this purpose, there were used microinjection containing Cas9 in the form of mRNA or protein, sgRNA, and a donor DNA vector with the VP6 gene into the cytoplasm of rabbit zygotes. A transgenic rabbit with the correct integration of the VP6 gene was obtained using the Cas 9 protein and was used to produce an experimental milkbased rotavirus vaccine.

Whey acidic protein (WAP) is the main protein of milk whey, its content in rabbit milk is about $15 \mathrm{~g} / \mathrm{l}$ [15], which makes the WAP gene a promising candidate for replacing the biologically active protein gene using the CRISPR/Cas9 system. The regulatory sequences of the WAP gene of mice and rabbits were used in the first classical works on transgenic animals production. Using the 5 ' region of the WAP rabbit gene in the genetic structure showed good results in classical transgenesis. The recombinant protein content in the milk of transgenic mice reached $10-20 \mathrm{mg} / \mathrm{ml}$. Integration by homologous recombination of a transgene with homologous arms to the WAP gene of a mouse or rabbit using CRISPR/Cas9 technology could ensure its operation under the control of full-size endogenous regulatory sequences of the whey acidic protein gene with the possibility of obtaining mouse models and rabbits-producers of recombinant proteins with its high content in milk [20,21]. However, there are no publications on obtaining mice and rabbits with targeted modification of the WAP gene.

The purpose of our last work was to create a plasmid containing homology arms to the sequences of the WAP rabbit gene, so that the DNA sequence of the biologically active protein could be integrated into it. If a reporter fluorescent protein gene is used as an insertion into the resulting plasmid matrix, this will allow us to evaluate visually the effectiveness of site-specific transgene integration using the components of CRISPR/Cas9 technology, followed by confirmation of the homologous recombination fact by polymerase chain reaction (PCR).

\section{Materials and methods}

All the work was performed in All-Russian Research Institute of Physiology, Biochemistry and Animal Nutrition in the framework of the state order 2019 on the theme 0445-20190030. The sequence of the WAP rabbit gene was taken from the GenBank database (entry NC_013678). The genomic DNA of the Californian rabbit breed rabbit was extracted from the tip of the ear. The selection of primers, construction of recombinant DNA, and restriction analysis were performed using the Vector NTI program. All primers, oligonucleotides, and plasmid DNA sequences were ordered from "Syntol" company $<$ http://www.syntol.ru>. For obtaining PCR amplifications of 5'-and 3' - homology arms (5'HA and 3'HA) with rabbit genomic DNA, we used pairs of primers W51 (AGATCTCTG CGAGGAGCTCTGTGCCT) / W5HA-2 (TACGGCCGGATGAGACAGCGCATGG) and W3HA-1 (TTCGGCCGTGTTGTCCACCAGCTGTG) / W3-2 (GGATCCAGATCTTTCT TCTGCGAGGCCTCTGTGCACC) with the entered sequences (underlined) for BglII, EagI and BamHI rectrictases (fig. 1).

The PCR procedure was performed on a DNA amplifier "Tertsik" ("DNA Technology LLC", Moscow). For intermediate cloning of PCR products, the pTZ57R/T plasmid and reagents of the InsTAclone PCR Cloning Kit (Thermo Scientific) were used. The transformation of competent E.coli Dh5aand TG1 cells was performed using the method and reagents of the Transform-Aid Bacterial Transformation Kit with our modifications. 
The extraction of plasmid DNA was performed using the GeneJET Plasmid Miniprep Kit with some modifications, by the classic method of alkaline lysis, and phenol-chloroform extraction method. The quality and quantity of DNA of isolated plasmids and restriction fragments were evaluated visually in UV light after electrophoresis in agarose gel (AG). DNA from AG was isolated using the Gene JET Gel Extraction Kit. The size of DNA fragments in AG was evaluated with DNA Ladder Mix (Fermentas). RNA guides were selected using on-line programs CHOPCHOP $<$ http://chopchop.cbu.uib.no/ $>$, CRISPR direct <http://crispr.dbcls.jp/>, CRISPOR v.4.8. <http://crispor.tefor.net/>. To create theCRISPR/Cas9 components, a pX330-U6-Chimeric_BB-CBh-hSpCas9 plasmid (Addgene plasmid \#42230, hereinafter - pX330) was used [22].

Rabbits were kept in the vivarium of All-Russian Research Institute of Physiology, Biochemistry and Animal Nutrition. We used female rabbits of California breed at the age of 1.5-2.5 years, weighing $2.5-3.5 \mathrm{~kg}$. In order to obtain the maximum number of zygotes in donor rabbits, superovulation was induced according to the previously used scheme [23]. Zygote isolation was performed surgically 17-19 hours after introduction of chorionic hormone. The collected zygotes were transferred to freshly prepared drops of the manipulating medium under mineral oil after washing in drops of the same medium. Microinjection into the male pronucleus of the zygote was performed in a Fonbrune camera on a device that included an inverted microscope with Nomarsky optics (Nikon) and a set of manipulators and microinjectors (Narishiga).

For long-term zygotes cultivation in vitro to the blastocyst stage, Ham's F-10 medium with the addition of $10 \%$ fetal bovine serum ("Eurobio", France) was used. Cultivation was carried out in $40 \mathrm{~mm}$ plastic Petri dishes in drops of medium with a volume of $40 \mu \mathrm{l}$ under light mineral oil ("Sigma" embryo tested) in the gas phase, $5 \% \mathrm{CO}_{2}$ in the air, at $\mathrm{t}=37^{\circ} \mathrm{C}$. Blastocysts developed from zygotes microinjected with a mixture containing genetic construction were visually evaluated under a fluorescent microscope under blue light. Blastocysts and embryos that stopped at late stages of development were collected one at a time in $10 \mu \mathrm{l}$ of lysing solution in microtubes and stored at $-20^{\circ} \mathrm{C}$ for following detection of transgene integration in their genome by PCR method.

\section{Results and discussion}

PCR amplificates of 5'- and 3'-arms of homology (5'HA and 3'HA) obtained with use of primers containing the corresponding restriction sites were cloned into the pTZ57R/T vector plasmid. The sequence of the cloned 5' region of the WAP rabbit gene showed a $100 \%$ match of the sequence with the published one. As a result, there was obtained a pTZHArbWAP plasmid containing 5'HA and 3'HA homology arms to the WAP gene, at the junction of which the site for EagI restrictase was integrated (fig. 1). 


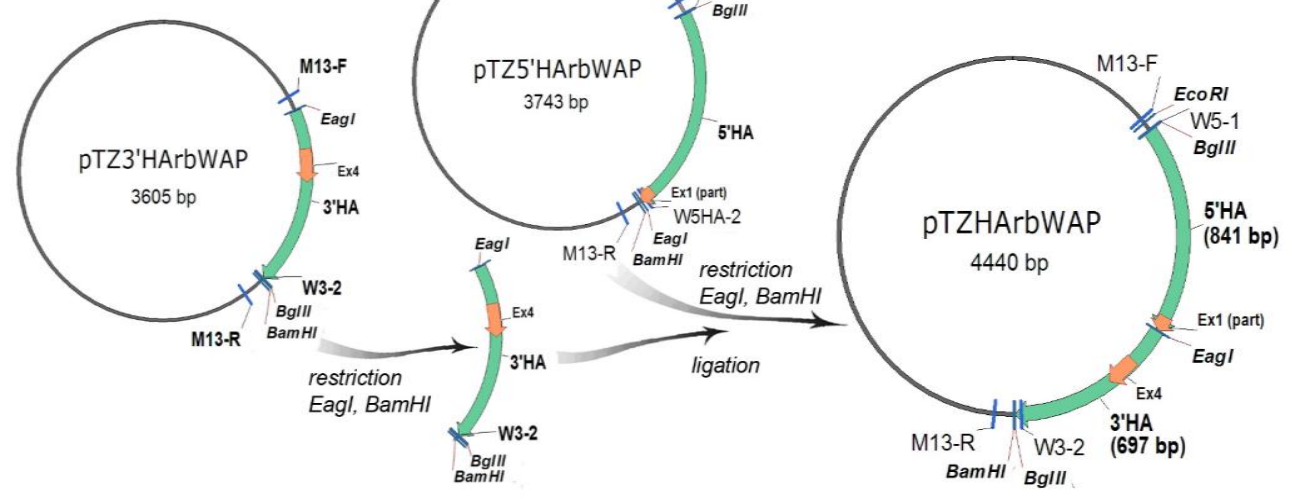

Fig. 1. Scheme of creating the main plasmid-vector containing $5^{\prime}$ and $3^{\prime}$ homology arms to the WAP rabbit gene: pTZHArbWAP. The working sites of restriction and binding sites of primers used in the work are indicated.

A fragment of cmvEGFP-bGHpolyA with EagI sticky ends containing a green fluorescent protein gene under a cytomegalovirus promoter $(\mathrm{cmv})$ and terminated by a polyA-sequence of the bull growth hormone gene, cut and purified from a previously created by us plasmid [24], was cloned into a prepared pTZHArbWAP. A pWAPcmvEGFP plasmid was obtained, which in circle or linearized form can be used as a reporter DNA matrix for homologous recombination with the WAP gene using CRISPR/Sas9 components. Restriction analysis of the plasmid showed that the cmvEGFP-bGHpolyA fragment integrated in it is inversely oriented. Because the cmvEGFP-bGHpolyA insertion is an independent expression cassette, its orientation in this case is relevant just for subsequent PCR detection. For knockout, local indels, or major deletion of the WAP gene, guide RNAs (gRNAs) sequences were selected. The pX330-511, pX330-51-, pX330-33 and pX330-31 plasmids encoding Cas9 and gRNAs [21] to the corresponding sites of the WAP gene were created with oligonucleotides for obtaining gRNAs processed according to the protocol [25] (fig. 2).

The effect of microinjection into zygote pronuclei of solutions with different concentrations of plasmids created by us with/without a linearized fragment of WAPcmvEGFP (1-WAPcmvEGF), separately - 1-WAPcmvEGF, on the development of rabbit embryos during in vitro cultivation to the blastocyst stage was verified. Blastocysts developed from zygotes microinjected with a mixture containing transgene (groups 3 and 4, table1) were visually evaluated under a fluorescent microscope under blue light (fig. 3).

The survival rate of embryos in the control and experimental groups was assessed. Embryos of experimental groups that developed to the blastocyst-morula stage were selected and frozen for following analysis of possible gene modifications by PCR followed by electrophoresis in agarose and polyacrylamide gels. The results of cultivation are shown in the table 1 . 


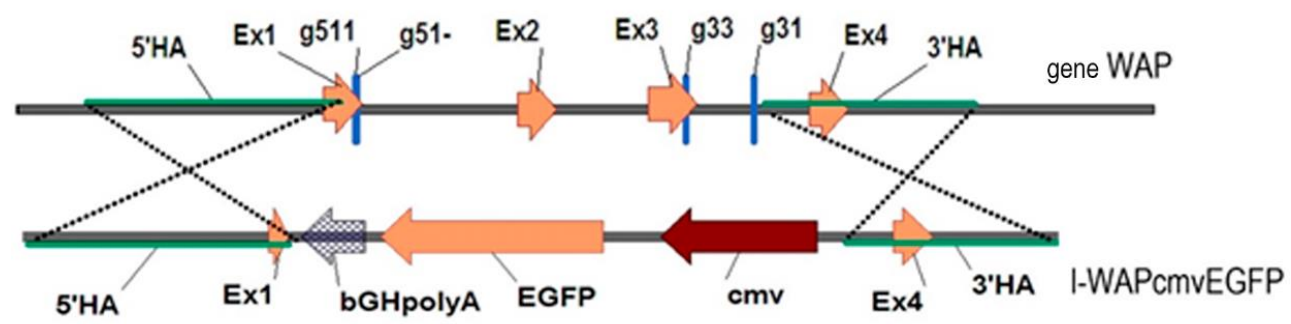

Fig. 2. Homologous recombination of a genetic construction containing homology arms with a rabbit WAP gene using CRISPR/Cas9 technology. Structural elements of the gene and construction are shown; g511, g51-, g31, g33-targets of gRNA; 5'HA and 3'HA - arms of homology.

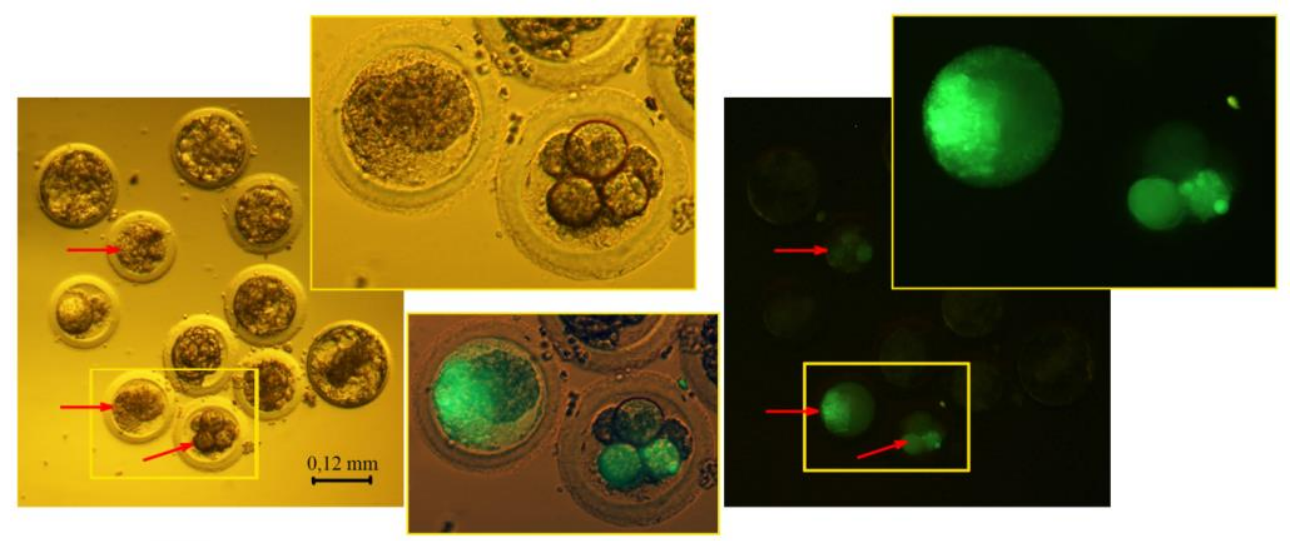

Fig. 3. Rabbit embryos cultured 5 days after microinjection into the pronucleus (one of the drops of group 3 embryos). The photos are taken in visible light (left) and blue light (right). In the center - the selected fragment in mixed light. Arrows indicate fluorescent embryos.

In groups 1 and 2 containing plasmid form (pX330-N) of components of CRISPR/Cas9 selected to target gene WAP, no significant inhibition of embryo development was found at both selected concentrations of total plasmid DNA. In our case, it was 10 and $20 \mathrm{ng} / \mu \mathrm{l}$ of the solution for MI. At $20 \mathrm{ng} / \mu \mathrm{l}$, the proportion of embryos that stopped at the 2-16 cell stage increased correspondingly, and the proportion of those that developed to the blastocyst-morula stage decreased. As a rule when using CRISPR/Cas9 in plasmid form, researchers adhere to a concentration of about $5 \mathrm{ng} / \mu \mathrm{l}$. In the work of Honda et al. [7] after MI $87 \%$ of rabbit embryos developed to pre-implantation state within a day, using $5 \mathrm{ng} / \mu \mathrm{l}$ pX330 for knockout of the tyrosinase gene. On the other hand, there is evidence of cytotoxicity of microinjection by gene-specific pX330 even in this concentration. For example, when the mouse zygote pX330 was added to the genes of the proteins Centrin 1 and Protamine 1, the proportion of those developed to the 2-cell stage was 91 and $50 \%$, respectively [26]. Probably, the different toxicity of gene-specific pX330 can be explained by the level of importance of the target gene for the development of the organism: the WAP gene does not belong to the "housekeeping" genes and its function is performed only during lactation. 
Table 1. Development in vitro of rabbit embryos microinjected by different compositions of DNA components ${ }^{\mathrm{a}}$.

\begin{tabular}{|c|c|c|c|c|c|c|c|}
\hline \multicolumn{3}{|c|}{$\begin{array}{l}\text { Groups of embryos, } \\
\text { Total DNA ng/ } \mu 1\end{array}$} & $\begin{array}{c}\text { Control } \\
0\end{array}$ & $\begin{array}{l}\# 1 \\
10\end{array}$ & $\begin{array}{l}\# 2 \\
20\end{array}$ & $\begin{array}{l}\# 3 \\
20\end{array}$ & $\begin{array}{l}\# 4 \\
10\end{array}$ \\
\hline \multirow{5}{*}{ Components } & \multicolumn{2}{|c|}{ 1-WAPcmvEGFP } & - & - & - & 10 & 10 \\
\hline & \multicolumn{2}{|c|}{$\mathrm{pX} 330-51^{-}$} & - & 2,5 & 5 & 2,5 & - \\
\hline & \multicolumn{2}{|c|}{ pX330-511 } & - & 2,5 & 5 & 2,5 & - \\
\hline & \multicolumn{2}{|c|}{ pX330-31 } & - & 2,5 & 5 & 2,5 & - \\
\hline & \multicolumn{2}{|c|}{ pX330-33 } & - & 2,5 & 5 & 2,5 & - \\
\hline \multicolumn{2}{|c|}{ Injected zygotes } & $\mathrm{N}$ & - & 52 & 33 & 105 & 137 \\
\hline \multicolumn{2}{|c|}{ Cultured zygotes } & $\mathrm{N}$ & 70 & 43 & 32 & 100 & 133 \\
\hline \multirow{4}{*}{$\begin{array}{l}\text { Developed to the } \\
\text { stage of }\end{array}$} & \multirow{2}{*}{$2-16$ cells } & $\mathrm{N}$ & 2 & 5 & 5 & 22 & 45 \\
\hline & & $\%^{\mathrm{b}}$ & 3 & 12 & 16 & 22 & 34 \\
\hline & \multirow{2}{*}{$\begin{array}{l}\text { blastocyst- } \\
\text { morula }\end{array}$} & $\mathrm{N}$ & 67 & 38 & 27 & 58 & 83 \\
\hline & & $\%^{\mathrm{b}}$ & 96 & 88 & 84 & 58 & 62 \\
\hline \multirow{4}{*}{ Glowed in UV } & \multirow{2}{*}{$2-16$ cells } & $\mathrm{N}$ & - & - & - & 14 & 24 \\
\hline & & $\%^{\mathrm{c}}$ & - & - & - & 63 & 53 \\
\hline & \multirow{2}{*}{$\begin{array}{c}\text { blastocyst- } \\
\text { morula }\end{array}$} & $\mathrm{N}$ & - & - & - & 4 & 15 \\
\hline & & $\%^{\mathrm{c}}$ & - & - & - & 7 & 18 \\
\hline \multicolumn{8}{|c|}{$\begin{array}{l}\text { a Total cultivation time is about } 96 \text { hours; } \\
\text { b from the number of cultured zygotes; }\end{array}$} \\
\hline
\end{tabular}

When adding GC to the components of CRISPR/Cas9 (group 3), as with microinjection by pure genetic construction (group 4), 80 and $96 \%$ of cultured embryos passed the 2 -cell stage, after which the embryo survival during the total cultivation time of 96 hours sharply decreased to 58 and $62 \%$, respectively. In groups without GC (Control, groups 1 and 2), the level of development to the blastocyst-morula stage was high - 96, 88, and $84 \%$, respectively.

In classical transgenesis, the integration of a transgene into the genome is random, and the number of integrated copies is unpredictable. It was assumed that in the case of homologous recombination using CRISPR/Cas9 technology, green fluorescent protein expression in the developing embryo in vitro would be an effective marker of successful site-specific integration of a single copy of the transgene.

In our work at the early stages of development, the number of luminous embryos was high (63 and 53\% in groups 3 and 4), and the glow was intensive. Such embryos did not develop further. At the blastocyst-morula stage, the number of fluorescent embryos decreased ( 7 and $18 \%$, respectively), and individual cells glowed in them, which is typical for transgenic mosaicism.

Earlier, using classical transgenesis methods, Chrenek and colleagues noted that after microinjection of GC containing the EGFP gene under a strong cmv promoter, $66-74 \%$ of rabbit embryos developed within 72 hours of cultivation to the morula stage, compared to $98 \%$ of intact rabbit embryos. The percentage of mosaicism was high [27]. This is consistent with our results. Reduced embryo viability may be associated with super expression of green fluorescent protein under cmv-promoter control, but not with the traumatic effect of MI.

In our 3 and 4 groups, the number and quality of luminous embryos were comparable, which makes it difficult to get a clear answer about the effectiveness and quality of transgenesis. It should be noted that we used a linearized form of the DNA matrix with BglII sticky ends, whereas it is considered that the DNA matrix in the plasmid form has less chance of random integration into the genome. On the other hand, a plasmid carrying a cystron unit is capable of EGFP self-expression prior to its lysis by endonucleases. The 
possibility of short-term EGFP expression by a functional linear GC also cannot be excluded.

We have developed a system of PCR and restriction analysis of possible genetic modifications of obtained rabbit embryos, which can answer a number of questions.

\section{Conclusions}

The All-Russian Research Institute of Physiology, Biochemistry and Animal Nutrition has experience in creating classical gene constructions for tissue-specific expression of transgenes in the mammary gland and obtaining transgenic rabbits-producers of biologically active human proteins with milk by microinjection into the zygote pronucleus [23]. We also obtained two lines of transgenic rabbits with non-specific EGFP expression (unpublished data). The use of CRISPR/Cas9 technology will allow to obtain transgenic rabbits-producers of biologically active proteins with higher efficiency. Currently, we have obtained site-specific to WAP rabbit gene components of the CRISPR/Cas9 system in plasmid form, and also a DNA matrix containing homology arms to this gene, into which a gene of a biologically active protein can be integrated [21]. All this makes it quite a real task to create GM rabbits that produce recombinant proteins with milk instead of whey acidic protein.

New genome editing technologies make it possible to obtain animals with precisely specified genetic modifications with high efficiency. Rabbits as biomodels of human diseases, bioreactors-producers are becoming more and more popular object of biomedical research and pharmaceutical production. Despite the obvious success of foreign, especially Chinese, geneticists in creating gene-edited rabbits, such work in Russia is practically absent.

\section{References}

1. Shepelev M V, Kalinichenko S V, Deykin A V and Korobko I V 2018 Acta Naturae 10(3) 40-47

2. Rybakova A V, Makarova M N and Makarov V G 2016 International journal of veterinary medicine 4 102-106

3. Bosze Z and Houdebine L M 2006 World Rabbit Sci. 14 1-14

4. Honda A and Ogura A 2017 J. Reprod. Dev. 63(5) 435-438

5. Zakhartchenko V, Flisikowska T, Li S, Richter T, Wieland H, Durkovic M, Rottmann O, Kessler B, Gungor T, Brem G et al. 2011 Biol. Reprod. 84 229-237

6. Yin M, Jiang W, Fang Z, Kong P, Xing F, Li Y, Chen X and Li S 2015 Sci. Rep. 5 16023

7. Honda A, Hirose M, Sankai T, Yasmin L, Yuzawa K, Honsho K, Izu H, Iguchi A, Ikawa M and Ogura A 2015 Exp. Anim. 64 31-37

8. Flisikowska T, Thorey I S, Offner S, Ros F, Lifke V, Zeitler B, Rottmann O, Vincent A, Zhang L, Jenkins S et al 2011 PLoSOne 6 e21045

9. Yang D, Zhang J, Xu J, Zhu T, Fan Y, Fan J and Chen Y E 2013 J. Vis. Exp. 81 e50957

10. Ji D, Zhao G, Songstad A, Cui X and Weinstein E J 2015 Transgenic Res. 24 227-235

11. Zhang J, Niimi M, Yang D, Liang J, Xu J, Kimura T, Mathew A V, Guo Y, Fan Y, Zhu $\mathrm{T}$ et al 2017 Arterioscler. Thromb. Vasc. Biol. 37(6) 1068-1075

12. Song J, Zhong J, Guo X, Chen Y, Zou Q, Huang J, Li X, Zhang Q, Jiang Z, Tang C et 
al 2013 Cell Res. 23 1059-1062

13. Li L, Zhang Q, Yang H, Zou Q, Lai C, Jiang F, Zhao P, Luo Z, Yang J, Chen Q et al 2017 J. Biol. Chem. 292(11) 4755-4763

14. Koloskova E M, Karkischenko V N, Yezersky V A, Petrova N V, Maksimenko S V and Matveyenko E L 2019 Journal Biomed. 15(4) 12-33

15. Maertens L, Lebas F and Szendrö Zs 2006 World Rabbit Sci. 14 205-230

16. van Veen H A, Koiter J, Vogelezang C J, van Wessel N, van Dam T, Velterop I, van Houdt K, Kupers L, Horbach D, Salaheddine M et al 2012 J. Biotechnol. 162(2-3) 319326

17. Soler E, Le Saux A, Guinut F, Passet B, Cohen R, Merle C, Charpilienne A, Fourgeux C, Sorel V, Piriou A et al 2005 Transgenic Res. 4 833-844

18. Soler E, Parez N, Passet B, Dubuquoy C, Riffault S, Pillot M, Houdebine L M and Schwartz-Cornil I 2007 Vaccine 25 6373-6380

19. Li H, Li Z, Xiao N, Su X, Zhao S, Zhang Y, Cui K, Liu Q and Shi D 2019 In Vitro Cell Dev. Biol. Anim. 55(8) 586-597

20. Koloskova E M, Ezerskii V A, Belova N V, Kutyin I V, Ryabykh V P, Trubitsina T P and Maksimenko S V 2018 Problems of biology of productive animals 2 19-30

21. Ezerskii V A and Koloskova E M 2019 Problems of biology of productive animals 4 22-35

22. Cong L, Ran F A, Cox D, Lin S, Barretto R, Habib N, Hsu P D, Wu X, Jiang W, Marraffini L A and Zhang F 2013 Science 10.1126/science.1231143

23. Ezerskiy V A, Shishimorova M S, Tevkin S I, Trubitsina T P, Koloskova E M, Bezborodova O A, Yakubovskaya R I, Maksimenko S V and Ryabykh V P 2013 Problems of biology of productive animals 4 33-52

24. Esersky V A, Tevkin S I and Shevchenko V G 2009 Problems of biology of productive animals 1 92-103

25. Menzorov A G, Lukyanchikova V A, Korablev A N, Serova I A and Fishman V S 2016 Russian Journal of Genetics: Applied Research 20(6) 930-944

26. Mashiko D, Fujihara Y, Satouh Y, Miyata H, Isotani A and Ikawa M 2013 Sci. Rep. 27(3) 3355

27. Chrenek P, Bauer M and Makarevich A V 2011 Zygote 19(1) 85-90 